\title{
Corrigendum: Estimation of the effects of radiotherapy treatment delays on tumour responses: A review
}

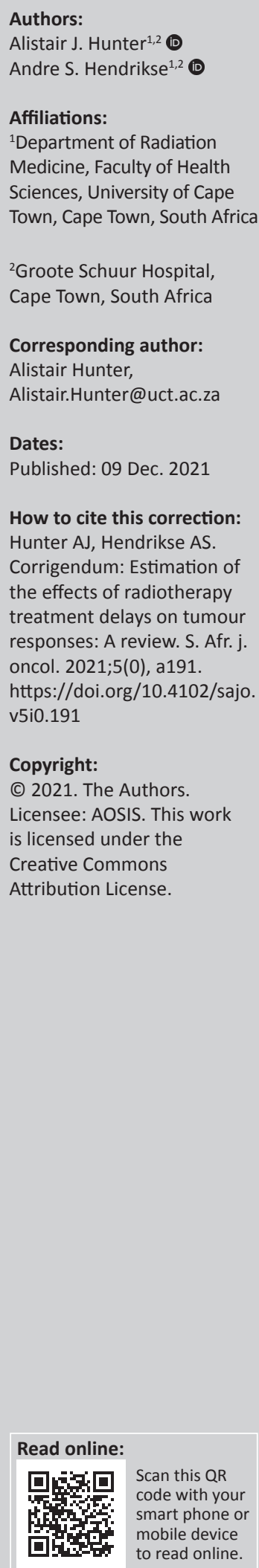

In the version of the article initially published, Hunter AJ, Hendrikse AS. Estimation of the effects of radiotherapy treatment delays on tumour responses: A review. S. Afr. j. oncol. 2020;4(0), a91. https://doi.org/10.4102/sajo.v4i0.91, the ORCID of the first author was given incorrectly. The correct ORCID should be https://orcid.org/0000-0002-6824-9342 instead of https://orcid. org/0000-0001-9282-8478 in the 'Authors' section.

This correction does not alter the study's findings of significance or overall interpretation of the study's results. The authors apologise for any inconvenience caused. 


\section{Estimation of the effects of radiotherapy treatment delays on tumour responses: A review}

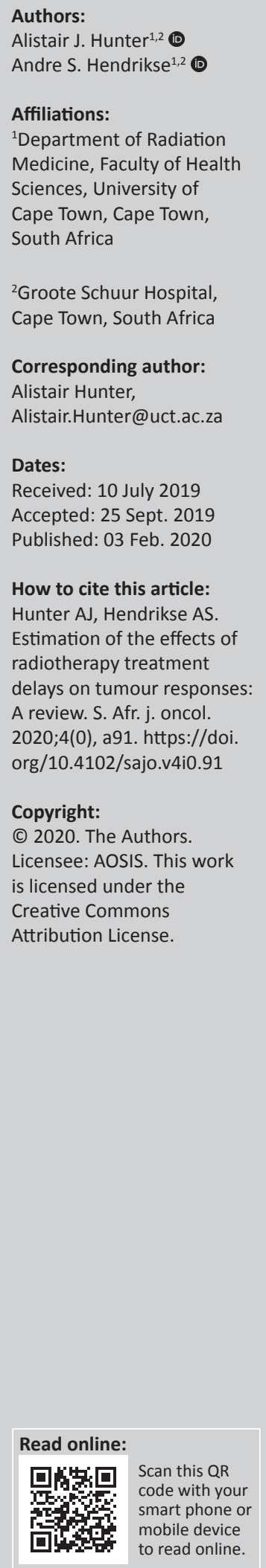

Background: The effects of radiotherapy treatment delays vary considerably depending on several factors, including tumour type, tumour characteristics, extent of delay and the radiation schedule. Both delays during treatment and delays in starting treatment may have an impact on tumour outcomes. In developing countries, particularly, budget constraints and overwhelming patient numbers may contribute to long waiting lists that may affect treatment efficacy. Empirical evidence on which to base treatment decisions and to motivate for additional resources is important.

Aim: The aim of this study was to review the evidence that radiotherapy treatment delays may affect tumour response in several common tumour types and to determine, where reported, estimates of specific, commonly applied parameters to incorporate time and proliferation.

Setting: Clinical radiotherapy of solid tumours.

Methods: A review of the literature from an online database and search engine using terms associated with treatment delays or interruptions for a range of common tumour types was conducted.

Results: There is evidence in several of the tumour types reviewed, including those of the head and neck, breast, cervix, prostate, lung, colorectal, anus, brain and bladder, that delays in radiotherapy can affect treatment outcomes. While, in most cases, delays in treatment are detrimental, there are certain examples cited where delays between other modalities and radiotherapy may be beneficial.

Conclusion: While levels of evidence vary, failure to take note of proliferative effects of tumours because of extensions in treatment may in many cases result in avoidable treatment failures. It is thus prudent for radiation oncology departments to have clear policies for avoiding and dealing with treatment delays.

Keywords: tumour repopulation; radiotherapy; treatment gaps; proliferation; overall treatment time.

\section{Introduction}

Many developing countries like South Africa are faced with limited resources and long radiotherapy waiting lists. Extensions in overall radiotherapy treatment times may be detrimental to patient outcomes because of accelerated tumour cell proliferation. Accelerated repopulation, that is, an increase in the rate of tumour cell division after a certain time into radiotherapy, may result from a decrease in tumour cell loss and an increase in tumour cell recruitment into the mitotic cycle, which occur when increased oxygen and nutrients become available when tumour cells are sterilised by irradiation. ${ }^{1,2}$ Accelerated repopulation may also be a result of radiationinduced activation of cell proliferation signalling. ${ }^{3}$

It is generally accepted that radiotherapy should ideally be completed without significant delays so as not to adversely affect tumour control or patient survival. However, given the extended nature of fractionated radiotherapy, which typically takes several weeks, it is common for treatments to be delayed for a variety of medical, logistic and social reasons. Delays in the initiation of treatment may also be detrimental to patient outcomes. The impact of alterations in overall treatment time or time till treatment may vary depending on tumour type, tumour stage, tumour biology, use of other anticancer treatments and whether any radiobiological compensation may have been applied to mitigate such alterations. While the primary focus of this review is on delays in radiotherapy, the issue of accelerated repopulation and effect of delays may also be relevant to other cancer treatment modalities, including surgery and chemotherapy. Thus, the relevance of delays in all modalities and possibly the aggregate effects of all treatments need to be considered. 
Radiotherapy treatment interruptions are common. Planned gaps because of weekends or public holidays are often incorporated into treatment schedules up front and are generally easier to accommodate than unplanned gaps where there may be less flexibility for compensation. Preplanned modifications in scheduling can be spread over the treatment to reduce any impacts on the therapeutic ratio. Compensation for unplanned gaps may be more complicated, particularly if there have been multiple interruptions and limited available time in which to apply any compensation before the detrimental effects of treatment extension become significant.

There are pragmatic approaches for compensating for gaps in radiotherapy. If a treatment extension is negligible or a tumour is slowly proliferating, no compensation may be necessary. However, knowledge of specific tumour kinetics is often lacking, and it is best to prevent gaps if possible to keep treatments 'as short as reasonably achievable', as suggested by the guidelines of the Royal College of Radiologists. ${ }^{4}$ If gaps have occurred, treatments should ideally be completed in the same overall time by treating on non-treatment days, delivering more than one fraction on a day or adding additional dose. If overall times are extended, compensation may also be possible by adding additional dose. The extra dose required would need to be determined using radiobiological dose equivalence estimates. The likelihood of normal tissue effects, whether tolerance is likely to be exceeded, and any effects on therapeutic ratio may also be estimated in this way. While treatment extensions are not considered good practice, there may be a case for extending treatments to keep fraction sizes small to maintain therapeutic advantage provided that the detriments of repopulation do not outweigh the advantages of normal tissue from fractionation.

Radiobiological effects may be estimated using an equation based on the linear-quadratic model:

$\mathrm{EQD} 2=n d(d+\alpha / \beta) /(2+\alpha / \beta),{ }^{5}$

[Eqn 1]

where $n$ is number of fractions, $d$ is dose per fraction and $\alpha / \beta$ is the fractionation dependence.

A modified version that includes time factors that may be relevant to tumour repopulation is:

$\mathrm{EQD} 2=n d(d+\alpha / \beta) /(2+\alpha / \beta)-(T-T k)$ Dprolif ${ }^{6}$

[Eqn 2]

where $T$ is the overall treatment time, $T k$ is the time at which accelerated repopulation starts and Dprolif is the dose 'lost' per day because of proliferation. This equation takes into consideration the induction of more rapid tumour growth after the initiation of treatment and the associated reduction in tumour effect. The accuracy of any predictions, however, will depend on the assumptions used. In many cases, accurate values of $T k$ and Dprolif are not available. Nevertheless, there is considerable information available that may allow reasonable determinations of possible outcomes, depending upon likely best and worst cases.
Apart from accelerated repopulation, which may occur after initiation of therapy, significant proliferation prior to the initiation of therapy may also negatively affect therapeutic effectiveness. Departments, particularly those in lesser resourced or developing countries, may have long waiting lists and limited flexibility to compensate for extensive gaps. It may be better to delay the start of radiotherapy rather than introducing gaps into treatment so as to avoid the detrimental effects of accelerated repopulation. However, delays in starting treatment may also have a negative impact on treatment outcomes because of excessive tumour growth prior to treatment, resulting in increased treatment failure. Such variables should be incorporated into any cost-benefit analysis when allocating resources to oncology units.

To assess the likely impact of time on tumour outcomes and determine what compensation for treatment delays may be necessary, tumour-type-specific information is required. Moreover, to minimise the impact of delays, it is important to establish suitable biological parameters that may be used for specific clinical scenarios. Representative values of $T k$ and Dprolif, and the effect of delays in treatment for specific tumour types and schedules need to be determined, as well as the influence of more modern approaches such as hypofractionation or chemoradiotherapy.

We have undertaken a review of the evidence for accelerated repopulation in a variety of common tumours and how alterations in overall treatment time or time before the start of radiotherapy may influence treatment outcome.

\section{Methods}

Medline and Google Scholar searches were used including terms such as 'gaps radiotherapy', 'interruptions radiotherapy', 'delays radiotherapy', 'breaks radiotherapy' and 'overall radiotherapy time' associated with various tumour sites.

In this review, evidence of the effects of treatment delays or extensions for head and neck, breast, cervix, prostate, lung, colorectal, brain and bladder cancers is presented besides estimates of certain relevant parameters pertaining to proliferative effects.

\section{Results and Discussion Head and neck tumours}

There is substantial evidence of significant rates of repopulation for squamous cell carcinomas of the head and neck. Both extensions in overall treatment time and delays till start of radiotherapy are detrimental and should be avoided.

\section{Overall treatment time}

Radiotherapy alone: It has been estimated that for laryngeal cancer, an increased dose of 0.5-0.6 Gy per day is required to maintain local control, with a kick-off time of not more than 
3 weeks after starting radiotherapy. ${ }^{7}$ A study of more than 2200 laryngeal cancer patients showed that prolongation of therapy by 1 day was associated with a decreased 2 -year control rate. ${ }^{8}$ For nasopharyngeal cancer, the hazard rate for locoregional failure was found to increase by approximately $3.3 \%$ for each day of treatment interruption. ${ }^{9}$

Chemoradiotherapy: More recent studies that incorporate chemotherapy have shown that radiotherapy delays may adversely affect treatment outcomes. Prolonged radiotherapy resulted in inferior survival and an increased likelihood of locoregional recurrence even with induction chemotherapy and concurrent chemotherapy. ${ }^{10}$ Treatments in excess of 7 weeks ${ }^{11}$ and 8 weeks ${ }^{12}$ were associated with inferior survival for patients receiving concurrent chemoradiotherapy. In another study, overall radiotherapy treatment times of more than 40 days significantly reduced metastasis-free survival by about $40 \%$ in patients with advanced disease treated with radiotherapy alone or with chemoradiotherapy. ${ }^{13}$

Time before treatment: Some studies suggested that increased waiting times between diagnosis and radiotherapy may not affect outcomes. ${ }^{14,15}$ The majority of studies, however, demonstrated that delays in initiating radiotherapy resulted in inferior outcomes. A meta-analysis of quality studies published between 1975 and 2005 showed that for patients treated with definitive radiotherapy, there was an increase in the absolute risk of recurrence of about $3.7 \%$ per month of delay. ${ }^{16}$ A multivariate analysis of a prospective database of 9896 patients with nasopharyngeal carcinoma showed that waiting time before radical radiotherapy of greater than 30 days was associated with inferior overall survival and disease-specific survival. ${ }^{17}$ Longer waiting times till start of surgery have also been shown to adversely affect survival. ${ }^{18,19}$ However, in a recent study, time between diagnosis and surgery did not influence survival..$^{20}$

Time between surgery and radiotherapy: A meta-analysis found that, for patients treated with postoperative radiotherapy, the absolute risk of recurrence increased by about $6.3 \%$ for every month that radiotherapy was delayed. ${ }^{16}$ An analysis of 15064 patients showed that survival decreased progressively with each day that the start of radiotherapy was delayed beyond 40 days post-surgery up till 55 days, after which further prolongation failed to have any additional effect on survival. ${ }^{20}$

\section{Breast tumours}

\section{Overall treatment time}

Evidence regarding the effect of overall radiotherapy treatment time is sparse. One study suggested that patients at low risk of recurrence may be minimally affected by treatment delays. ${ }^{21}$ However, another study of 853 patients with stage I-III breast cancer, all of whom had undergone surgery, and $84 \%$ of whom had received adjuvant chemo- or hormonal therapy, demonstrated a reduction in overall survival and 5-year local control for an extension in radiotherapy of more than 1 week. $^{22}$

\section{Time between surgery and radiotherapy}

Delays do not affect outcome: Some studies showed little effect of waiting 6-8 weeks between surgery and radiotherapy for early, localised disease..$^{23,24}$

Delays improve outcome: A comparison of three timing tertiles (1-36, 37-53 and 54-112 days) between lumpectomy and radiotherapy for patients with stage I or II, node-negative disease demonstrated that 10 -year metastasis-free survival and disease-specific survival were superior for those who had a longer interval between treatments. ${ }^{25}$

Delays worsen outcome: A review of 46 studies found that recurrences were increased if time between surgery and radiotherapy exceeded 8 weeks. ${ }^{26}$ Another systematic review suggested that 12 weeks was the cut-off. ${ }^{27}$ A study of more than 18000 patients showed that an interval of 6 weeks was significant with respect to loss of local control, with a hazard ratio of $1.19 .^{28}$ In a recent review, it was concluded that, to maintain acceptable outcomes $(<3 \%-4 \%$ loss of survival), time between surgery and radiotherapy should not exceed 20 weeks. $^{29}$ Other recommendations were that surgery should occur within 90 days of diagnosis, chemotherapy within 120 days of diagnosis and radiotherapy within 365 days of chemotherapy.

\section{Cervical tumours}

Overall treatment time: There is substantial evidence that tumour cell repopulation occurs as a result of extensions in the overall radiotherapy treatment time and negatively affects outcomes. A loss of overall survival and local control of $0.6 \%$ per day, irrespective of tumour grade, ${ }^{30}$ and $1 \%$ per day for advanced disease ${ }^{31}$ was reported for extensions beyond 52-55 days. An earlier study suggested that, for patients with advanced disease, extensions beyond 30 days may adversely affect outcome. ${ }^{32}$ In a 2004 study, overall survival, disease-free survival and local control were found to be superior for treatment times of 60 days or less. ${ }^{33}$

Combination chemoradiotherapy may influence the effects of treatment extensions. A retrospective review of 113 patients with stage IB2-IIIB disease, who received whole pelvis radiotherapy with concurrent chemotherapy and brachytherapy to the cervix, confirmed the importance of completing the brachytherapy within 8 weeks to avoid pelvic failure. ${ }^{34}$ A study of 2594 patients, the majority of whom were treated with chemoradiotherapy, showed that for early-stage patients (I-IIB), survival was worse when treatment times were longer than 56 days. However, for advanced disease (IIIIVA), no effect on outcomes could be demonstrated. ${ }^{35} \mathrm{~A}$ small retrospective study of 166 patients receiving chemoradiotherapy and 206 patients receiving radiotherapy 
found a trend for treatment durations of 62 or more days to result in a worse disease-free survival, but only in women treated with radiotherapy alone. ${ }^{36}$ A large study of 7209 patients receiving chemoradiotherapy could not demonstrate a difference in the overall survival in patients treated in 8 weeks or less versus those treated in more than 8 weeks. Survival, however, was found to be inferior when the treatment duration exceeded 10 weeks. ${ }^{37}$ It is possible that chemotherapy combined with radiotherapy may, to some extent, inhibit radiation-induced accelerated repopulation.

\section{Tk and Dprolif}

From clinical data, a $T k$ value of around 19 days was estimated. ${ }^{38}$

For an assumed Tk of 28 days, Dprolif values of $0.22-0.31$ Gy/day for relatively radiosensitive tumours and $0.5 \mathrm{~Gy} /$ day for radioresistant tumours were estimated. ${ }^{33}$

\section{Time before treatment}

Delaying the start of radical radiotherapy may adversely affect outcome. ${ }^{39}$ A large study comprising 9081 patients showed that delaying surgery, radiotherapy or chemoradiotherapy by 4 or more months after diagnosis resulted in a 2.3 times greater risk of death. ${ }^{40}$ However, an analysis of 14924 patients with non-metastatic cancer treated with radiotherapy or chemoradiotherapy demonstrated that time till treatment start did not significantly affect survival, possibly because patients with more advanced disease were treated earlier. ${ }^{41}$

\section{Time between surgery and radiotherapy}

A longer than 4-week interval between surgery and radiotherapy was shown to impact negatively on recurrencefree survival but not overall survival. ${ }^{42}$

\section{Prostate tumours}

\section{Overall treatment time}

Some studies suggested that prostate cancers are relatively slow growing, ${ }^{43}$ and that delays of a few days may not significantly affect outcomes. ${ }^{44}$ Others suggested that delays may be more serious depending on tumour stage and radiation dose. ${ }^{45}$ An early study showed that radiotherapy treatment times of more than 9 weeks, compared to less than 7 weeks, had no effect on local control or survival of patients with T1c tumours. However, for patients with T2 localised tumours, local control and survival were inferior when treatment exceeded 9 weeks if the radiation dose was less than or equal to $72 \mathrm{~Gy}$, but not if the radiation dose exceeded $72 \mathrm{~Gy}$. No association between treatment time and outcome was found for T3 tumours. ${ }^{46}$ In a retrospective study of 4839 patients, overall treatment times longer than 52 days had a significant effect on biochemical failure for patients treated with at least 70 Gy. A 1-week increase in treatment time was associated with a $6 \%$ increase in biochemical failure. ${ }^{47}$ A study including 30\% high-risk, 30\% low-risk and 40\% mediumrisk patients showed that those receiving doses of $74 \mathrm{~Gy}$ or more were not disadvantaged in terms of a 4-year biochemical failure by treatment extensions. However, for those receiving less than $74 \mathrm{~Gy}$, a $15 \%$ increase in biochemical failure was observed if treatment was extended by 2 or more days. ${ }^{48}$ In a recent study of 1728 patients, 113 patients with high-risk disease, it was found that four or more treatment interruptions did not significantly affect biochemical failure, metastasis or survival for those treated with at least $74 \mathrm{~Gy} .{ }^{49}$

\section{Tk and Dprolif}

An analysis of clinical data from previous studies yielded an estimated Tk of 5-6 weeks, with a doubling time of 9-34 days. ${ }^{50}$ In a more recent study, a similar Tk of 31 days, but a more rapid doubling time of 5 days, was estimated, ${ }^{51}$ suggesting wide variability and potential differences in the impact of treatment delays.

Dprolif values of $0.24 \mathrm{~Gy} /$ day, $^{47} 0.34 \mathrm{~Gy}^{4}$ day $^{52}$ and 0.52 Gy/day ${ }^{51}$ were estimated. The latter Dprolif value suggests that some prostate cancers repopulate rapidly, being comparable to squamous cell carcinomas of the head and neck. Assumptions that prostate cancers are always slow growing and, thus, require less urgent treatment may be unfounded.

\section{Time between prostatectomy and radiotherapy}

For pT3 node-negative prostate cancer with undetectable prostate specific antigen (PSA) levels post-prostatectomy, patients are often offered either immediate adjuvant radiotherapy or PSA monitoring with salvage radiotherapy when there is biochemical failure. The latter approach allows patients who do not relapse to avoid potential side effects from radiotherapy. A retrospective study of 244 patients who received radiotherapy within 6 months of radical prostatectomy and 141 who received salvage radiotherapy later showed that metastasis-free survival and overall survival at 8 years were not significantly different..$^{53}$ Another retrospective study of 2190 patients suggested that delaying radiotherapy may even be beneficial, as it seemed to improve recovery from erectile dysfunction and urinary incontinence after surgery. ${ }^{54}$ However, in a retrospective single institution study of 718 patients, although survival or metastasis rates were not different, 10-year biochemical failure was approximately $20 \%$ lower and freedom-from-androgendeprivation therapy was about $8 \%$ higher in men receiving immediate adjuvant radiotherapy. ${ }^{55}$

\section{Non-small cell lung cancer}

\section{Overall treatment time}

There is evidence that delays during radiotherapy are detrimental. ${ }^{56,57}$ An analysis of data from 1244 patients with unresectable non-small cell lung cancer (NSCLC) suggested that accelerated repopulation resulted in a loss of local control of about $1.7 \%$ per day for extensions beyond $3-4$ weeks. ${ }^{58}$ 
Another study found that a cut-off of 45 days made a difference to local progression-free survival. ${ }^{59}$ A retrospective analysis demonstrated that risk of death may increase by $2 \%$ per day for treatment prolongations of 5 days or more. ${ }^{60}$ A more recent analysis of 14154 patients with stage III NSCLC treated with concurrent chemoradiotherapy found that treatment delays significantly affected the overall survival. Median overall survival was reduced from 22.7 months for patients without delays to 18.6 months for patients with delays. A hazard ratio of 1.21 was estimated using multivariate analysis. ${ }^{61}$

\section{Dprolif}

A Dprolif value of $0.45 \mathrm{~Gy} /$ day was estimated for each day of treatment extension beyond 20 days. ${ }^{62}$

\section{Time before radiotherapy}

Clinical studies that have investigated the impact of delaying the initiation of radiotherapy on tumour response have yielded mixed results. Some studies suggest that delays may not affect outcome. ${ }^{63,64}$ However, a small study of 29 lung cancer patients indicated that a median delay of 54 days between diagnosis and the start of radiotherapy resulted in $21 \%$ of potentially curable patients becoming incurable. ${ }^{65}$

Another study showed that $29 \%$ of patients became unsuitable for radical radiotherapy after treatment delays that resulted in the mean tumour volume increasing from $105 \mathrm{cc}$ to $198 \mathrm{cc} .{ }^{66}$ Some studies have shown that delaying the initiation of radiotherapy after chemotherapy may negatively affect outcomes, possibly as a result of chemotherapyinduced accelerated tumour cell proliferation. ${ }^{67,68}$ There is also evidence that delays in initiating radiotherapy may have beneficial effects, ${ }^{69,70}$ possibly because patients with more advanced disease were treated more promptly.

\section{Small cell lung cancer}

Concurrent chemoradiotherapy is the standard treatment for limited disease small cell lung cancer. Because chemotherapy may also initiate accelerated repopulation, it is possible that increased time between chemotherapy and thoracic irradiation initiation, in addition to prolonged overall radiotherapy treatment time, may be problematic.

\section{Time between chemotherapy and radiotherapy}

There is evidence that the time between chemotherapy and radiotherapy makes a difference. A systematic review and meta-analysis of seven randomised clinical trials using platinum-based chemotherapy with radiotherapy indicated that the 5-year survival rate was higher for those patients whose radiotherapy was initiated within 30 days of starting chemotherapy, with a hazard ratio of $0.65 .{ }^{71}$ However, a phase 3 randomised trial did not show inferior survival and progression-free survival with delayed radiotherapy. ${ }^{72}$

\section{Overall treatment time}

An analysis of data from six trials that combined platinum or anthracycline-based chemotherapy with radiotherapy showed that patients who completed chemoradiotherapy more quickly had a superior 5-year survival rate, with a hazard ratio of $0.6 .^{73}$

\section{Colorectal}

\section{Overall treatment time}

In the Stockholm III trial, no difference in local recurrences, metastases, relapse-free survival or overall survival was observed when comparing $5 \times 5$ Gy (EQD2 = 31.3 Gy) and $25 \times 2$ Gy $($ EQD2 $=50 \mathrm{~Gy}) .{ }^{74}$ The finding that tumour response was not better with the $25 \times 2$ Gy regime is, possibly, evidence of repopulation occurring with this more protracted schedule.

\section{Tk and Dprolif}

In one study, accelerated repopulation was shown to occur but only in slowly proliferating tumours in female patients, with a $T k$ of about 4 weeks. ${ }^{75}$

In another study, Dprolif values for rectal cancer of 0.15 and $0.37 \mathrm{~Gy} /$ day were estimated. ${ }^{76}$

\section{Time before radiotherapy}

A prospective Danish study showed that delays of 60 days or more between diagnosis and radiotherapy were associated with a $69 \%$ inferior survival for patients with rectal, but not colon, cancer. ${ }^{77}$ Subsequent studies, however, indicated that delays of up to 120 days $^{78}$ and even up to 100 weeks ${ }^{79}$ did not affect survival in colorectal cancer patients.

\section{Time between surgery and chemotherapy}

Although not the main topic of this article, it is interesting to note that delays between surgery and chemotherapy in excess of 8 weeks ${ }^{80}$ and 3 months ${ }^{81}$ were associated with a significant reduction in survival.

\section{Anus}

\section{Overall treatment time}

A study that estimated the proliferation parameters of 22 squamous and four basaloid epidermoid carcinomas of the anus yielded a median potential tumour doubling time of 4.1 days. ${ }^{82}$ This suggests that anal carcinomas may repopulate as rapidly as cervical carcinomas.

A retrospective analysis of 937 patients who had been part of Radiation Therapy Oncology Group (RTOG) trials 87-04 and 98-11 showed that overall chemoradiotherapy treatment times of more than 53 days resulted in inferior local control (hazard ratio [HR] 1.96), although the duration of radiotherapy per se did not affect tumour response. ${ }^{83}$ Several smaller studies involving chemoradiotherapy indicated that treatment extensions are detrimental. ${ }^{84,85,86}$ However, a retrospective analysis of 101 patients treated with 
chemoradiation demonstrated that a 5-year local control and colostomy-free survival rates were not adversely affected when treatment was interrupted by more than six cumulative treatment days, compared to six or less. ${ }^{87}$

\section{Gliomas}

\section{Tk and Dprolif}

From patients treated with surgery and radiotherapy, Tk values of 37 days $^{88}$ and 44 days $^{89}$ were estimated. Dprolif was estimated to be around $0.3 \mathrm{~Gy} /$ day. ${ }^{88,89}$ The short tumour doubling time of 3 days estimated for high grade (III/IV) gliomas suggested that such tumours may have an even higher Dprolif (approximately 0.5 Gy/day) and are likely to be adversely affected by treatment extensions..$^{90}$

\section{Time between surgery and radiotherapy}

Delays worsen outcome: An analysis of 345 patients given temozolomide and radiotherapy after surgery indicated that survival was significantly reduced if radiotherapy was initiated more than 6 weeks after surgery compared to 2 or less weeks. ${ }^{91}$ A large retrospective study comprising 12738 patients showed that there was a significant survival advantage when chemoradiotherapy was initiated less than 35 days after surgery. ${ }^{92}$

Delays do not affect outcome: Several recent studies, many of which included modern chemotherapy or chemoradiotherapy, could not show an effect of delaying the start of postoperative radiotherapy, ${ }^{93,94,95,96}$ including a metaanalysis of 12 retrospective studies including 5212 patients. ${ }^{97}$

Delays improve outcome: A retrospective study of 2855 patients in the RTOG database found that delaying radiotherapy for a few weeks after surgery did not seem to affect survival and that an interval of more than 4 weeks improved survival. It was suggested that time may allow recovery from surgeryrelated brain damage and, possibly, reversal of postoperative hypoxia, which could influence tumour radiosensitivity. ${ }^{98}$ A study of 2535 patients whose chemoradiotherapy was initiated within 13 weeks of surgery showed that those who waited at least 4 weeks before commencing radiotherapy had a better survival rate. ${ }^{99}$ Starting radiotherapy within 3 weeks after surgery for paediatric medulloblastomas has been shown to have a negative impact on survival compared to when radiotherapy was started more than 3 weeks, but less than 90 days, after surgery. ${ }^{100}$

\section{Bladder tumours}

While radical cystectomy is a standard treatment for bladder cancer, transurethral resection followed by concurrent chemoradiotherapy yields a similar cure rate while maintaining bladder preservation.

\section{Overall treatment time}

Studies with 147 patients ${ }^{101}$ and with 379 patients ${ }^{102}$ showed that radiotherapy treatment prolongations did not affect local

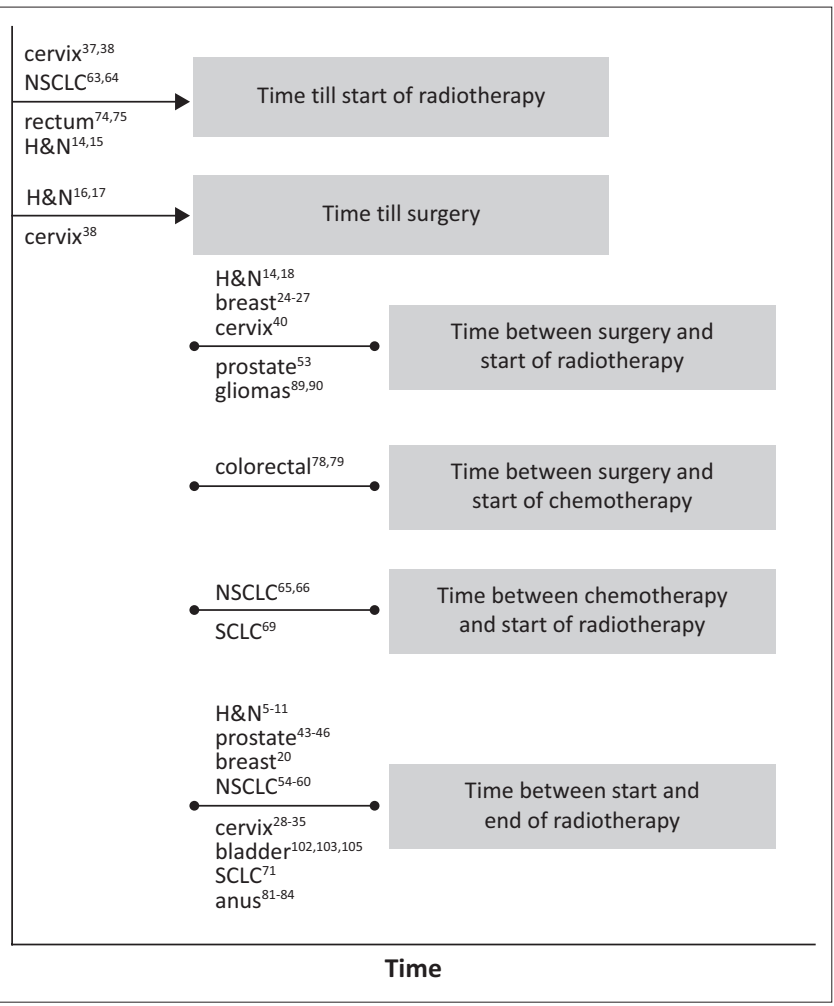

Note: The reported studies were not performed by the authors but the Figure 1 representation of findings is the authors' own work. For more information, please refer to the reference list as indicated.

FIGURE 1: Tumours may be negatively affected by extensions in time to initiate treatment, by extensions in time between treatments and by extensions in the overall radiotherapy treatment time.

control. However, the relatively short estimated potential tumour doubling time of 3-8 days for bladder cancer suggests that treatment delays might adversely impact tumour response to radiotherapy. ${ }^{103}$ In a small study, 2-year overall survival was $38 \%$ for patients who completed radiotherapy within 8 weeks, compared to $0 \%$ for those who completed their treatment over a longer period. ${ }^{104}$ More recently, a study of 29 patients demonstrated a trend for treatment interruptions of more than 5 days to negatively affect survival. ${ }^{105}$ The European Association of Urology has suggested that a course of radiotherapy should not extend beyond 6-7 weeks, so as to minimise the effect of repopulation. ${ }^{106}$

\section{Tk and Dprolif}

From a study that showed that local control was compromised by radiotherapy treatment extensions, it was estimated that the $T k$ for accelerated repopulation was about 5-6 weeks, with a Drolif of 0.36 Gy/day. ${ }^{107}$

Overall, as summarized in Figure 1, extensions in therapy as a result of delays before or during treatment, or increased intervals between different modalities, may compromise treatment outcomes of many tumour types.

\section{Conclusions}

Evidence for accelerated repopulation during therapy and cell division in the interval between diagnosis and initiating 
treatment has been described in many tumour types. Therefore, it is important to avoid delays if possible and to compensate accordingly where relevant. All radiation oncology departments should have a policy on gaps and other treatment delays and be suitably informed as to how to assess treatment deviations and implement remedial action if warranted. Treatment waiting lists need to be periodically reviewed and the likely effects on outcomes assessed. Such information is useful to prioritise certain high-risk tumours or to motivate for increased resources or efficiencies where waiting times for treatment of highly proliferative tumours are found to be excessive.

\section{Acknowledgements Competing interests}

The authors have declared that no competing interest exists.

\section{Authors' contributions}

All authors contributed equally to this work.

\section{Ethical considerations}

This article followed all ethical standards for research without direct contact with human or animal subjects.

\section{Funding information}

This research received no specific grant from any funding agency in the public, commercial or not-for-profit sectors.

\section{Data availability statement}

Data sharing is not applicable to this article as no new data were created or analysed in this study.

\section{Disclaimer}

The views and opinions expressed in this article are those of the authors and do not necessarily reflect the official policy or position of any affiliated agency of the authors.

\section{References}

1. Hansen O, Grau C, Bentzen SM, Overgaard J. Repopulation in the SCCVII squamous cell carcinoma assessed by an in vivo-in vitro excision assay. Radiothe Oncol. 1996;39(2):137-144. https://doi.org/10.1016/0167-8140(96)01728-8

2. Trott K, Kummermehr J. Accelerated repopulation in tumours and normal tissues. Radiother Oncol. 1991;22(3):159-60.

3. Schmidt-Ullrich R, Mikkelsen R, Dent $P$, et al. Radiation-induced proliferation of the human A431 squamous carcinoma cells is dependent on EGFR tyrosine phosphorylation. Oncogene. 1997;15(10):1191. https://doi. org/10.1038/sj.onc.1201275

4. RCR. The timely delivery of radical radiotherapy: Guidelines for the management of unscheduled treatment interruptions [hompage on the Internet]. 4th ed. London: The Royal College Radiologists; 2019 [cited 2019 Jun 05]. Available from: https://www.rcr.ac.uk/system/files/publication/field_publication files/ bfco191 radiotherapy-treatment-interruptions.pdf

5. Withers HR, Thames HD, Peters $L$. A new isoeffect curve for change in dose per fraction. Radiother Oncol. 1983;1(2):187-191. https://doi.org/10.1016/s0167 8140(83)80021-8

6. Bentzen SM, Joiner, MC. The linear-quadratic approach in clinical practice. In Joiner M, Van Der Kogel, A, editors. Basic clinical radiobiology. 4th ed. London: Hodder, 2009; p. 126

7. Slevina N, Hendry JH, Roberts SA, Agren-Crongvist A. The effect of increasing the treatment time beyond three weeks on the control of T2 and T3 laryngeal cance using radiotherapy. Radiother Oncol. 1992;24(4):215-220. https://doi.org/ 10.1016/0167-8140(92)90226-k
8. Robertson C, Robertson AG, Hendry JH, et al. Similar decreases in local tumor control are calculated for treatment protraction and for interruptions in the radiotherapy of carcinoma of the larynx in four centers. Int J Radiat Oncol Biol radiotherapy of carcinoma of the larynx in four centers. Int J Radiat Oncol Biol
Phys. 1998;40(2):319-329. https://doi.org/10.1016/s0360-3016(97)00716-5

9. Kwong DLW, Sham JST, Chua DTT, Choy DTK, Au GKH, Wu PM. The effect of interruptions and prolonged treatment time in radiotherapy for nasopharyngeal
carcinoma. Int J Radiat Oncol Biol Phys. 1997;39(3):703-710. https://doi. org/10.1016/s0360-3016(97)00339-8

10. Sher DJ, Posner MR, Tishler RB, et al. Relationship between radiation treatment time and overall survival after induction chemotherapy for locally advanced head-and-neck carcinoma: A subset analysis of TAX 324. Int J Radiat Oncol Biol Phys. 2011;81(5):e813-e818. https://doi.org/10.1016/j.jirobp.2010.12.005

11. Cannon DM, Geye HM, Hartig GK, et al. Increased local failure risk with prolonged radiation treatment time in head and neck cancer treated with concurrent chemotherapy. Head Neck. 2014;36(8):1120-1125. https://doi. org/10.1002/hed.23419

12. Shaikh T, Handorf EA, Murphy CT, Mehra R, Ridge JA, Galloway TJ. The impact of radiation treatment time on survival in patients with head and neck cancer. Int J Radiat Oncol Biol Phys. 2016;96(5):967-975. https://doi.org/10.1016/j. ijrobp.2016.08.046

13. Dahlke S, Steinmann $\mathrm{D}$, Christiansen $\mathrm{H}$, et al. Impact of time factors on outcome in patients with head and neck cancer treated with definitive radio (chemo) therapy. In Vivo. 2017;31(5):949-955. https://doi.org/10.21873/invivo.11152

14. Barton MB, Morgan G, Smee R, Tiver KW, Hamilton C, Gebski V. Does waiting time affect the outcome of larynx cancer treated by radiotherapy? Radiothe Oncol. 1997;44(2):137-141. https://doi.org/10.1016/s0167-8140(97)00093-5

15. León $X$, De Vega $M$, Orús $C$, Morán J, Vergés J, Quer $M$. The effect of waiting time on local control and survival in head and neck carcinoma patients treated with radiotherapy. Radiother Oncol. 2003;66(3):277-281. https://doi.org/10.1016/ S0167-8140(03)00022-7

16. Chen Z, King W, Pearcey R, Kerba M, Mackillop WJ. The relationship between waiting time for radiotherapy and clinical outcomes: A systematic review of the literature. Radiother Oncol. 2008;87(1):3-16. https://doi.org/10.1016/j. radonc.2007.11.016

17. Liang $H$, Xiang $Y-Q$, Lv $X$, et al. Survival impact of waiting time for radical radiotherapy in nasopharyngeal carcinoma: A large institution-based cohort study from an endemic area. Eur J Canc. 2017;73:48-60. https://doi. org/10.1016/j.ejca.2016.12.009

18. Van Harten MC, Hoebers FJ, Kross KW, Van Werkhoven ED, Van Den Brekel MW Van Dijk BA. Determinants of treatment waiting times for head and neck cance in the Netherlands and their relation to survival. Oral Oncol. 2015;51(3):272278. https://doi.org/10.1016/j.oraloncology.2014.12.003

19. Murphy CT, Galloway TJ, Handorf EA, et al. Survival impact of increasing time to treatment initiation for patients with head and neck cancer in the United States. J Clin Oncol. 2016;34(2):169. https://doi.org/10.1200/JCO.2015.61.5906

20. Ho AS, Kim S, Tighiouart $M$, et al. Quantitative survival impact of composite treatment delays in head and neck cancer. Cancer. 2018;124(15):3154-3162. https://doi.org/10.1002/cncr.31533

21. Hébert-Croteau N, Freeman CR, Latreille J, Brisson J. Delay in adjuvant radiation treatment and outcomes of breast cancer - A review. Breast Canc Res Treat. 2002;74(1):77-94. https://doi.org/10.1023/a:1016089215070

22. Bese NS, Sut PA, Ober A. The effect of treatment interruptions in the postoperative irradiation of breast cancer. Oncology. 2005;69(3):214-223. https://doi.org/10.1159/000087909

23. Corradini $\mathrm{S}$, Niemoeller OM, Niyazi M, et al. Timing of radiotherapy following breast-conserving surgery: Outcome of 1393 patients at a single institution. Strahlenther Onkol. 2014;190(4):352. https://doi.org/10.1007/s00066-013-0540-x

24. Hébert-croteau N, Freeman CR, Latreille J, Rivard M, Brisson J. A populationbased study of the impact of delaying radiotherapy after conservative surgery for breast cancer. Breast Cancer Res Treat. 2004;88(2):187-196. https://doi. org/10.1007/s10549-004-0594-7

25. Jobsen JJ, van der Palen J, Ong F, Meerwaldt JH. Timing of radiotherapy and survival benefit in breast cancer. Breast Cancer Res Treat. 2006;99(3):289-294. https://doi.org/10.1007/s10549-006-9217-9

26. Huang J, Barbera L, Brouwers M, Browman G, Mackillop WJ. Does delay in starting treatment affect the outcomes of radiotherapy? A systematic review. J Clin Oncol. 2003;21(3):555-563. https://doi.org/10.1200/JCO.2003.04.171

27. Jack RH, Holmberg L. Waiting times for radiotherapy after breast cancer. BMJ. 2010;340:c1007. https://doi.org/10.1136/bmj.c1007

28. Punglia RS, Saito AM, Neville BA, Earle CC, Weeks JC. Impact of interval from breast conserving surgery to radiotherapy on local recurrence in older women with breast cancer: Retrospective cohort analysis. BMJ. 2010;340:c845. https:// doi.org/110.1136/bmj.c845

29. Bleicher RJ. Timing and delays in breast cancer evaluation and treatment. Ann Surg Oncol. 2018;25(10):2829-2838. https://doi.org/10.1245/s10434-018-6615-2

30. Petereit DG, Sarkaria JN, Chappell R, et al. The adverse effect of treatment prolongation in cervical carcinoma. Int J Radiat Oncol Biol Phys. 1995;32(5):1301-1307. https://doi.org/10.1016/0360-3016(94)00635-X

31. Girinsky $T$, Rey A, Roche B, et al. Overall treatment time in advanced cervical carcinomas: A critical parameter in treatment outcome. Int J Radiat Oncol Biol Phys. 1993;27(5):1051-1056. https://doi.org/10.1016/0360-3016(93)90522-w

32. Fyles A, Keane TJ, Barton M, Simm J. The effect of treatment duration in the local control of cervix cancer. Radiother Oncol. 1992;25(4):273-279. https://doi. org/10.1016/0167-8140(92)90247-r 
33. Gasinska A, Fowler JF, Lind BK, Urbanski K. Influence of overall treatment time and radiobiological parameters on biologically effective doses in cervical cancer patients treated with radiation therapy alone. Acta Oncol. 2004;43(7):657-666 https://doi.org/10.1080/02841860410018511

34. Song S, Rudra S, Hasselle MD, et al. The effect of treatment time in locally advanced cervical cancer in the era of concurrent chemoradiotherapy. Cancer. 2013;119(2):325-331. https://doi.org/10.1002/cncr.27652

35. Lin SM, Ku HY, Chang TC, Liu TW, Hong JH. The prognostic impact of overall treatment time on disease outcome in uterine cervical cancer patients treated primarily with concomitant chemoradiotherapy: A nationwide Taiwanese cohort study. Oncotarget. 2017;8(49):85203-85213. https://doi.org/10.18632/ oncotarget.19617

36. Shaverdian N, Gondi V, Sklenar KL, et al. Effects of treatment duration during concomitant chemoradiation therapy for cervical cancer. Int J Radiat Oncol Biol Phys. 2013;86(3):562-568. https://doi.org/10.1016/j.ijrobp.2013.01.037

37. Tergas Al, Neugut Al, Chen L, Burke WM, Hershman DL, Wright JD. Radiation duration in women with cervical cancer treated with primary chemoradiation: A population-based analysis. Cancer Invest. 2016;34(3):137-147. 1https://doi.org /10.3109/07357907.2015.1131291

38. Huang Z, Mayr NA, Gao M, et al. Onset time of tumor repopulation for cervical cancer: First evidence from clinical data. Int J Radiat Oncol Biol Phys. 2012;84(2):478-484. https://doi.org/10.1016/j.ijrobp.2011.12.037

39. E C, Dahrouge S, Samant R, Mirzaei A, Price J. Radical radiotherapy for cervix cancer: The effect of waiting time on outcome. Int J Radiat Oncol Biol Phys. 2005;61(4):1071-1077. https://doi.org./10.1016/j.ijrobp.2004.09.030

40. Shen SC, Hung YC, Kung PT, Yang WH, Wang YH, Tsai WC. Factors involved in the delay of treatment initiation for cervical cancer patients: A nationwide population-based study. Medicine. 2016;95(33):e4568. https://doi. org/10.1097/MD.0000000000004568

41. Ramey SJ, Asher D, Kwon D, et al. Delays in definitive cervical cancer treatment An analysis of disparities and overall survival impact. Gynecol Oncol. 2018; 149(1):53-62. https://doi.org/10.1016/j.ygyno.2017.12.010

42. Hanprasertpong J, Jiamset I, Geater A, Leetanaporn K, Peerawong T. Impact of time interval between radical hysterectomy with pelvic node dissection and initial adjuvant therapy on oncological outcomes of early stage cervical cance J Gynecol Oncol. 2017;28(4):e42. https://doi.org/10.3802/jgo.2017.28.e42

43. Haustermans $\mathrm{K}$, Hofland I, Van HP, et al. Cell kinetic measurements in prostate cancer. Int J Radiat Oncol Biol Phys. 1997;37(5):1067-1070. https://doi. org/10.1016/s0360-3016(96)00579-2

44. Lai P, Pilepich M, Krall J, et al. The effect of overall treatment time on the outcome of definitive radiotherapy for localized prostate carcinoma: The Radiation Therapy Oncology Group 75-06 and 77-06 experience. Int J Radiat Oncol Biol Phys. 1991;21(4):925-933. https://doi.org/10.1016/0360-3016(91)90731-i

45. Amdur RJ, Parsons JT, Fitzgerald LT, Million RR. The effect of overall treatment time on local control in patients with adenocarcinoma of the prostate treated with radiation therapy. Int J Radiat Oncol Biol Phys. 1990;19(6):1377-1382. https://doi.org/10.1016/0360-3016(90)90347-m

46. Perez CA, Michalski J, Mansur D, Lockett MA. Impact of elapsed treatment time on outcome of external-beam radiation therapy for localized carcinoma of the prostate. Cancer J. 2004;10(6):349-356. https://doi.org/10.1097/00130404 200411000-00004

47. Thames HD, Kuban D, Levy LB, et al. The role of overall treatment time in the outcome of radiotherapy of prostate cancer: An analysis of biochemical failure in 4839 men treated between 1987 and 1995. Radiother Oncol. 2010;96(1):612. https://doi.org/10.1016/j.radonc.2010.03.020

48. Liauw SL, Liauw SH. Prolongation of total treatment time because of infrequently missed days of treatment is not associated with inferior biochemical outcome after dose-escalated radiation therapy for prostate cancer. Int J Radiat Oncol Bio Phys. 2011;81(3):751-757. https://doi.org/10.1016/j.ijrobp.2010.06.054

49. Dong $\mathrm{Y}$, Zaorsky NG, Li T, et al. Effects of interruptions of external beam radiation therapy on outcomes in patients with prostate cancer. J Med Imaging Radiat Oncol. 2018;62(1):116-121. https://doi.org/10.1111/1754-9485.12675

50. Gao M, Mayr NA, Huang Z, Zhang H, Wang JZ. When tumor repopulation starts? The onset time of prostate cancer during radiation therapy. Acta Oncol. 2010;49(8):1269-1275. https://doi.org/10.3109/0284186X.2010.509737

51. Pedicini P, Strigari L, Benassi M. Estimation of a self-consistent set of radiobiological parameters from hypofractionated versus standard radiation https://doi.org/10.1016/j.ijrobp.2012.11.033

52. Miralbell R, Roberts SA, Zubizarreta E, Hendry JH. Dose-fractionation sensitivity of prostate cancer deduced from radiotherapy outcomes of 5,969 patients in seven international institutional datasets: $\alpha / \beta=1.4(0.9-2.2)$ Gy. Int J Radiat Oncol Biol Phys. 2012;82(1):e17-e24. https://doi.org/10.1016/j.ijrobp.2010. 10.075

53. Fossati N, Karnes RJ, Boorjian SA, et al. Long-term impact of adjuvant versus early salvage radiation therapy in pT3NO prostate cancer patients treated with radical prostatectomy: Results from a multi-institutional series. Eur Urol. 2017;71(6):886-893. https://doi.org/10.1016/j.eururo.2016.07.028

54. Zaffuto E, Gandaglia G, Fossati N, et al. Early postoperative radiotherapy is associated with worse functional outcomes in patients with prostate cancer. J Urol. 2017;197(3):669-675. https://doi.org/10.1016/j.juro.2016.09.079

55. Buscariollo DL, Drumm M, Niemierko A, et al. Long-term results of adjuvant versus early salvage postprostatectomy radiation: A large single-institutional experience. Pract Radiat Oncol. 2017;7(2):e125-e133. https://doi.org/10.1016/j. prro.2016.10.010
56. Cox JD, Pajak TF, Asbell S, et al. Interruptions of high-dose radiation therapy decrease longterm survival of favorable patients with unresectable nonsmall cell carcinoma of the lung: Analysis of 1244 cases from 3 radiation therapy oncology group (RTOG) trials. Int J Radiat Oncol Biol Phys. 1993;27(3):493-498. https:// doi.org/10.1016/0360-3016(93)90371-2

57. Bremjit $P$, Robinson $G$, Weaver $R$, Bowen $S$, Rengan $R$, Patel $S$. Is overall treatment time a predictive factor in radiation therapy for non-small cell lung cancer? Int J Radiat Oncol Biol Phys. 2014;90(1):S639-S40. https://doi.org/10.1016/j. ijrobp.2014.05.1896

58. Fowler JF, Chappell R. Non-small cell lung tumors repopulate rapidly during radiation therapy. Int J Radiat Oncol Biol Phys. 2000;46(2):516-517. https://doi. org/10.1016/s0360-3016(99)00364-8

59. Chen M, Jiang GL, Fu XL, et al. The impact of overall treatment time on outcomes in radiation therapy for non-small cell lung cancer. Lung Cancer. 2000;28(1):11-19. https://doi.org/10.1016/s0169-5002(99)00113-0

60. Machtay M, Hsu C, Komaki R, et al. Effect of overall treatment time on outcomes after concurrent chemoradiation for locally advanced non-small-cell lung carcinoma: Analysis of the Radiation Therapy Oncology Group (RTOG) experience. Int J Radiat Oncol Biol Phys. 2005;63(3):667-671. https://doi. org/10.1016/j.ijrobp.2005.03.037

61. McMillan MT, Ojerholm E, Verma V, et al. Radiation treatment time and overal survival in locally advanced non-small cell lung cancer. Int J Radiat Oncol Bio Phys. 2017;98(5):1142-1152. https://doi.org/10.1016/j.ijrobp.2017.04.004

62. Koukourakis $M$, Hlouverakis $G$, Kosma L, et al. The impact of overall treatment time on the results of radiotherapy for nonsmall cell lung carcinoma. Int J Radiat Oncol Biol Phys. 1996;34(2):315-322. https://doi.org/10.1016/0360-3016(95) 02102-7

63. Falk SJ, Girling DJ, White RJ, et al. Immediate versus delayed palliative thoracic radiotherapy in patients with unresectable locally advanced non-small cell lung cancer and minimal thoracic symptoms: Randomised controlled trial. BMJ. 2002;325(7362):465. https://doi.org/10.1136/bmj.325.7362.465

64. Vinod S, Kaplan A. P-747 Growth of non-small cell lung cancer from diagnosis to radiotherapy treatment. Lung Cancer. 2005;49(Supp 2):S315. https://doi. org/10.1016/S0169-5002(05)81240-1

65. O'Rourke N, Edwards R. Lung cancer treatment waiting times and tumour growth Clin Oncol. 2000;12(3):141-144. https://doi.org/10.1053/clon.2000.9139

66. Everitt S, Plumridge N, Herschtal A, et al. The impact of time between staging $\mathrm{PET} / \mathrm{CT}$ and definitive chemo-radiation on target volumes and survival in patients with non-small cell lung cancer. Radiother Oncol. 2013;106(3):288291. https://doi.org/10.1016/j.radonc.2013.02.010

67. El Sharouni SY, Kal HB, Battermann JJ. Accelerated regrowth of non-small-cell lung tumours after induction chemotherapy. Br J Cancer. 2003;89:2184. https:// doi.org/10.1038/sj.bjc.6601418

68. Chen CP, Weinberg VK, Jahan TM, Jablons DM, Yom SS. Implications of delayed initiation of radiotherapy: Accelerated repopulation after induction chemotherapy for stage III non-small cell lung cancer. J Thorac Oncol. 2011;6(11):1857-1864. https://doi.org/10.1097/JTO.0b013e318229a41e

69. Myrdal G, Lambe M, Hillerdal G, Lamberg K, Agustsson T, Ståhle E. Effect of delays on prognosis in patients with non-small cell lung cancer. Thorax. 2004;59(1):45.

70. Diaconescu R, Lafond C, Whittom R. Treatment delays in non-small cell lung cancer and their prognostic implications. J Thorac Oncol. 2011;6(7):1254-1259. https://doi.org/10.1097/JTO.0b013e318217b623

71. Pijls-Johannesma M, De Ruysscher D, Vansteenkiste J, Kester A, Rutten I, Lambin P. Timing of chest radiotherapy in patients with limited stage small cell lung cancer: Timing of chest radiotherapy in patients with limited stage small cell lung cancer: A systematic review and meta-analysis of randomised controlled trials. Can
Treat Rev. 2007;33(5):461-473. https://doi.org/10.1016/j.ctrv.2007.03.002

72. Sun JM, Ahn YC, Choi EK, et al. Phase III trial of concurrent thoracic radiotherapy with either first-or third-cycle chemotherapy for limited-disease small-cell lung cancer. Ann Oncol. 2013;24(8):2088-2092. https://doi.org/10.1093/annonc/ mdt140

73. De Ruysscher D, Pijls-Johannesma M, Bentzen SM, et al. Time between the first day of chemotherapy and the last day of chest radiation is the most important predictor of survival in limited-disease small-cell lung cancer. J Clin Oncol. 2006;24(7):1057-1063. https://doi.org/10.1200/JCO.2005.02.9793

74. Erlandsson J, Holm T, Pettersson D, et al. Optimal fractionation of preoperative radiotherapy and timing to surgery for rectal cancer (Stockholm III): A multicentre, randomised, non-blinded, phase 3, non-inferiority trial. Lancet Oncol. 2017;18(3):336-346. https://doi.org/10.1016/S1470-2045(17)30086-4

75. Gasinska A, Richter P, Darasz Z, et al. Gender-related differences in repopulation and early tumor response to preoperative radiotherapy in rectal cancer patients. J Gastrointest Surg. 2011;15(9):1568-1576. https://doi.org/10.1007/s11605011-1589-4

76. Suwinski R, Wzietek I, Tarnawski R, et al. Moderately low alpha/beta ratio for rectal cancer may best explain the outcome of three fractionation schedules of preoperative radiotherapy. Int J Radiat Oncol Biol Phys. 2007;69(3):793-799. https://doi.org/10.1016/j.ijrobp.2007.03.046

77. Iversen LH, Antonsen S, Laurberg S, Lautrup M. Therapeutic delay reduces survival of rectal cancer but not of colonic cancer. Br J Surg. 2009;96(10):11831189. https://doi.org/10.1002/bjs.6978

78. Pruitt SL, Harzke AJ, Davidson NO, Schootman M. Do diagnostic and treatment delays for colorectal cancer increase risk of death? Cancer Causes Control. 2013;24(5):961-977. 1https://doi.org/10.1007/s10552-013-0172-6

79. Murchie $P$, Raja E, Brewster D, et al. Time from first presentation in primary care to treatment of symptomatic colorectal cancer: Effect on disease stage and survival. Br J Cancer. 2014;111(3):461. https://doi.org/10.1038/bjc.2014.352 
80. Tevis SE, Kohlnhofer BM, Stringfield S, et al. Postoperative complications in rectal cancer patients are associated with delays in chemotherapy which lead to worse disease free and overall survival: Rectal cancer complications to worse disease free and overall survival: Rectal cancer complications
chemotherapy. Dis Colon Rectum. 2013;56(12). https://doi.org/10.1097/ DCR.0b013e3182a857eb

81. Cheung WY, Neville BA, Earle CC. Etiology of delays in the initiation of adjuvant chemotherapy and their impact on outcomes for stage II and III rectal cancer. Dis Colon Rectum. 2009;52(6):1054-1064. https://doi.org/10.1007/DCR. 0b013e3181a51173

82. Wong CS, Tsang RW, Cummings BJ, et al. Proliferation parameters in epidermoid carcinomas of the anal canal. Radiother Oncol. 2000;56(3):349-353. https://doi. org/10.1016/s0167-8140(00)00213-9

83. Ben-Josef E, Moughan J, Ajani JA, et al. Impact of overall treatment time on survival and local control in patients with anal cancer: A pooled data analysis of radiation therapy oncology group trials 87-04 and 98-11. J Clin Oncol. 2010;28(34):5061-5066. https://doi.org/10.1200/JCO.2010.29.1351

84. Huang K, Haas-Kogan D, Weinberg V, Krieg R. Higher radiation dose with a shorter treatment duration improves outcome for locally advanced carcinoma of anal canal. World J Gastroenterol. 2007;13(6):895. https://doi.org/10.3748/ wjg.v13.i6.895

85. Graf R, Wust $\mathrm{P}$, Hildebrandt $\mathrm{B}$, et al. Impact of overall treatment time on local control of anal cancer treated with radiochemotherapy. Oncology. 2003;65(1):14-22. https://doi.org/10.1159/000071200

86. Bazan JG, Hara W, Hsu A, et al. Intensity-modulated radiation therapy versus conventional radiation therapy for squamous cell carcinoma of the anal canal. Cancer. 2011;117(15):3342-3351. https://doi.org/10.1002/cncr.25901

87. Janssen S, Zu Eissen JM, Kolbert G, Bremer M, Karstens JH, Meyer A. Anal cancer treated with radio-chemotherapy: Correlation between length of treatment interruption and outcome. Int J Colorectal Dis. 2009;24(12):1421. https://doi org/10.1007/s00384-009-0775-2

88. Pedicini $\mathrm{P}$, Fiorentino $\mathrm{A}$, Simeon $\mathrm{V}$, et al. Clinical radiobiology of glioblastoma multiforme. Strahlenther Onkol. 2014;190(10):925-932.

89. Milyukov S, Lysak Y, Panshin G, Kharchenko N, Tsallagova Z, Izmailov T. PO-0995: Estimation of radiobiology parameters of infiltrative low-grade gliomas WHO Grade II. Radiother Oncol. 2017;123:S549. https://doi.org/10.1016/S01678140(17)31431-7

90. Do V, Gebski V, Barton MB. The effect of waiting for radiotherapy for grade III/ IV gliomas. Radiother Oncol. 2000;57(2):131-136. https://doi.org/10.1016/ S0167-8140(00)00257-7

91. Spratt DE, Folkert M, Zumsteg ZS, et al. Temporal relationship of post-operative radiotherapy with temozolomide and oncologic outcome for glioblastoma. J Neurooncol. 2014;116(2):357-363. https://doi.org/10.1007/s11060-0131302-4

92. Pollom EL, Fujimoto DK, Han SS, Harris JP, Tharin SA, Soltys SG. Newly diagnosed glioblastoma: Adverse socioeconomic factors correlate with delay in radiotherapy initiation and worse overall survival. J Radiat Res. 2018;59(suppl_1):i11-i18. https://doi.org/10.1093/jrr/rrx103

93. Seidlitz A, Siepmann T, Löck S, Juratli T, Baumann M, Krause M. Impact of waiting time after surgery and overall time of postoperative radiochemotherapy on treatment outcome in glioblastoma multiforme. Radiat Oncol. 2015;10(1):172. https://doi.org/10.1186/s13014-015-0478-5
94. Blumenthal DT, Won M, Mehta MP, et al. Short delay in initiation of radiotherapy for patients with glioblastoma-effect of concurrent chemotherapy: A secondary analysis from the NRG Oncology/Radiation Therapy Oncology Group database. Neuro-Oncol. 2018;20(7):966-974.
https://doi.org/10.1093/neuonc/noy017

95. Azizi AA, Paur S, Kaider A, et al. Does the interval from tumour surgery to radiotherapy influence survival in paediatric high grade glioma? Strahlenthe Onkol. 2018;194(6):552-559. https://doi.org/10.1007/s00066-018-1260-z

96. Louvel G, Metellus P, Noel G, et al. Delaying standard combined chemoradiotherapy after surgical resection does not impact survival in newly diagnosed glioblastoma patients. Radiother Oncol. 2016;118(1):9-15. https:// doi.org/10.1016/j.radonc.2016.01.001

97. Loureiro LVM, Da Silva Victor E, Callegaro-Filho D, et al. Minimizing the uncertainties regarding the effects of delaying radiotherapy for Glioblastoma: A systematic review and meta-analysis. Radiother Oncol. 2016;118(1):1-8. https://doi.org/10.1016/j.radonc.2015.11.021

98. Blumenthal DT, Won M, Mehta MP, et al. Short delay in initiation of radiotherapy may not affect outcome of patients with glioblastoma: A secondary analysis from the radiation therapy oncology group database. J Clin Oncol. 2009;27(5):733. https://doi.org/10.1200/JCO.2008.18.9035

99. Nathan JK, Brezzell AL, Kim MM, Leung D, Wilkinson DA, Hervey-Jumper SL. Early initiation of chemoradiation following index craniotomy is associated with decreased survival in high-grade glioma. J Neurooncol. 2017;135(2):325-333. https://doi.org/10.1007/s11060-017-2577-7

100. Chin AL, Moding EJ, Donaldson SS, et al. Survival impact of postoperative radiotherapy timing in pediatric and adolescent medulloblastoma. NeuroOncol. 2018;20(8):1133-1141.

101. De Neve W, Lybeert ML, Goor C, Crommelin MA, Ribot JG. Radiotherapy for T2 and T3 carcinoma of the bladder: The influence of overall treatment time. Radiother Oncol. 1995;36(3):183-188. https://doi.org/10.1016/0167-8140(95) 01586-6

102. Moonen L, vd Voet H, de Nijs R, Horenblas S, Hart AA, Bartelink H. Muscleinvasive bladder cancer treated with external beam radiation: Influence of total dose, overall treatment time, and treatment interruption on local control. Int $J$ Radiat Oncol Biol Phys. 1998;42(3):525-530. https://doi.org/10.1016/s03603016(98)00263-6

103. Wilson GD, McNally NJ, Dische $\mathrm{S}$, et al. Measurement of cell kinetics in human tumours in vivo using bromodeoxyuridine incorporation and flow cytometry. $\mathrm{Br}$ J Cancer. 1988;58(4):423-431. https://doi.org/10.1038/bjc.1988.234

104. Hsieh $\mathrm{CH}$, Chung SD, Chan PH, et al. Intensity modulated radiotherapy for elderly bladder cancer patients. Radiat Oncol. 2011;6:75. https://doi.org/10.1186/1748717X-6-75

105. Janssen S, Manig L, Schild SE, Rades D. Radiotherapy of primary or recurrent bladder cancer in the very elderly. Anticancer Res. 2017;37(6):3287-3290. https://doi.org/10.21873/anticanres.11694

106. Stenzl A, Cowan NC, De Santis M, et al. Treatment of muscle-invasive and metastatic bladder cancer: Update of the EAU guidelines. Eur Urol. 2011;59(6):1009-1018. https://doi.org/10.1016/j.eururo.2011.03.023

107. Maciejewski B, Majewski S. Dose fractionation and tumour repopulation in radiotherapy for bladder cancer. Radiother Oncol. 1991;21(3):163-170. https:// doi.org/10.1016/0167-8140(91)90033-d 